\title{
Note on Conventions
}

Following the convention among classicists and others who study the ancient world, I have used в.c.e. (before the Common Era) and c.e. (Common Era) to describe dates otherwise written as B.C. and A.D.

In quotations from original sources, I have silently modernized some spellings for intelligibility, so that $i$ becomes $j, u$ becomes $v$, and vice versa. I have retained punctuation and italicization.

I cite Greek and Latin sources according to the conventional numbering of books, lines, and so on, found in the volumes of the Loeb Classical Library.

Translations are my own, unless otherwise specified. 
